\title{
The Growing Trend of Health Coaches in Team-Based Primary Care Training A Multicenter Pilot Study
}

Nicole M. Gastala, MD; Peter M. Wingrove, BS; Anne H. Gaglioti, MD; Winston Liaw, MD, MPH; Andrew Bazemore, MD, MPH

BACKGROUND AND OBJECTIVES: Team-based care with health coaches has improved the quality and cost effectiveness of chronic disease management and prevention. Clinical health coaches partner with patients to identify health goals, create action plans, overcome barriers to change, reinforce physician recommendations, and coordinate care. It is important to train resident physicians to practice in team-based settings. To date, there have been no studies of resident family physician exposure to health coaches.

METHODS: We surveyed 465 residency directors through a larger omnibus survey sent out by CERA; the response rate was $53.7 \%$. Directors were asked about resident exposure to health coaches, the types of patients seen by health coaches, and the training background of the health coaches. We used chi-square tests to examine the relationship among these variables and program characteristics including status as a patient-centered medical home.

RESULTS: Almost two-thirds of the programs reported at least some residents had exposure to health coaches. Residents who trained in continuity sites with a PCMH certification of level 3 were more likely to have any exposure to health coaches $(P<.05)$. There were multiple significant relationships between populations of patients seen and the training background of health coaches.

CONCLUSIONS: To improve quality, reduce costs, and become more patient centered, primary care is rapidly transforming into a team sport with a broadening roster of new players, including health coaches. This study documents positive rates of resident exposure to health coaches but also great variability in types and amount of exposure that merit further investigation and exploration of ways to grow family medicine residency contact with a diversifying practice team.

(Fam Med. 2018;50(7):526-30.)

doi: 10.22454/FamMed.2018.459897

$\mathbf{H}$ alf of primary care patients have at least one chronic condition. ${ }^{1}$ Managing and preventing these diseases are cornerstones of primary care, but practice constraints impede quality care. ${ }^{2}$ Of those with chronic disease, many neither take medications as prescribed nor implement lifestyle recommendations. ${ }^{3,4}$
Team-based strategies are being developed to address these issues. One successful model uses health coaches to support self-management. ${ }^{5-7}$ Health coaches have been shown to improve the quality and cost-effectiveness of managing chronic diseases like diabetes, hypertension, hyperlipidemia, mental health, and obesity.5,8-14
Health coaches are behavior change specialists who partner with patients to identify goals and barriers, reinforce recommendations, and coordinate care. They can be established team members (such as registered nurses [RNs], medical assistants [MAs], and psychologists) or can be unlicensed, such as health workers. Training varies, but generally consists of active listening, nonjudgmental communication, motivational interviewing, and encouragement of self-management skills. ${ }^{15}$ Visits can occur in person or telephonically. ${ }^{16}$ Health coaches differ from health educators as they develop goals and plans, and differ from case managers, as they may be unlicensed. ${ }^{8}$

As payment becomes population based, residencies have an opportunity to prepare residents to work within teams, and understanding current trends can enhance curricula. ${ }^{5}$ There have been no previous studies related to health coaches in family medicine residencies. The purpose of this study was to characterize the involvement of health coaches in family medicine resident education.

From University of Illinois Health Mile Square Community Health Center, Chicago, IL (Dr Gastala); the Robert Graham Center, Washington, DC (Mr Wingrove, Drs Liaw and Bazemore); and the National Center for Primary Care-Morehouse school of Medicine, Atlanta, GA (Dr Gaglioti). 


\section{Methods}

The Council of Academic Family Medicine Educational Research Alliance distributed a survey (Appendix A) from July to August 2016. ${ }^{17}$ The American Academy of Family Physicians Institutional Review Board approved the project. Emails were delivered to directors for the 495 Accreditation Council for Graduate Medical Education-accredited family medicine residencies. Nonrespondents were encouraged to participate with four follow-up emails. We excluded those opting out, with undeliverable emails, who were no longer program directors, or who failed to answer the health coach exposure question.

In addition to a set of recurring questions regarding demographic and organizational information, secondary outcomes included resident opportunities to observe and work with health coaches. ${ }^{17}$ Respondents were asked about plans to incorporate health coaches in the next 1 to 2 years. Respondents identified the specific populations addressed by health coaches and up to three training backgrounds. We grouped programs where all residents had exposure and programs where some residents had exposure into an "any exposure" category. Patient-centered medical home (PCMH) status was divided into five categories (National Center for Quality Assurance [NCQA] levels 1-3, not certified, or in the process of certifying). ${ }^{18}$

We conducted chi-square tests among programs with any health coach exposure to determine if health coach utilization for a specific population was associated with training backgrounds and if residency exposure to health coaches varied by characteristics.

\section{Results}

The overall response rate was $53.7 \%$ (245/465), though five were excluded for failing to answer the health coach question. Of the remaining, $158(65.8 \%)$ reported some residents had exposure to health coaches. Of these, $109(69.0 \%)$ reported that all residents had exposure, and 49 $(31.0 \%)$ reported some did. Ninetynine programs offered opportunities to observe or work with health coaches; of these, $89.9 \%$ reported all residents had exposure. In residencies without health coaches, $14.9 \%$ of programs reported that all residents were exposed, and $57.4 \%$ reported that no residents had exposure $(P<.01)$. Of the 109 programs where all residents were exposed, 79 $(72.5 \%)$ offered training on working with health coaches. This was true of four $(8.2 \%)$ of the programs where some were exposed.

There were differences in program characteristics (Table 1). For example, residencies in midsize communities and with a lower percentage of international medical graduate residents were more likely to be exposed to health coaches $(P<.05)$. Residents training in level 3 NCQA PCMHs were more likely to have any exposure compared to those who are not $(P<.05$, Table 2$)$. Residents training at sites which were not PCMHs and were not applying for PCMH status were less likely to be exposed $(P<.1)$. Of the 118 programs without health coach exposure, $41(34.75 \%)$ planned to incorporate health coaches into residency training in the next 1 to 2 years.

The backgrounds of health coaches varied based on how they were used. Programs with health coaches available to all patients were less likely to use licensed practical nurses (LPNs) $(P<.01$,Table 3$)$. Programs where health coaches supported chronic disease management were more likely to use RNs $(P<.05)$, LPNs $(P<.05)$, or those with health coach certificates $(P<.05)$. Programs using health coaches for obesity were more likely to use MAs $(P<.05)$ or trained health coaches $(P<.01)$. Programs using health coaches for mental health were more likely to use psychologists $(P<.05)$ or coaches without specified backgrounds $(P<.1)$.

\section{Discussion}

We found high exposure to health coaches, with residents in a level 3
PCMH more likely to be exposed than their peers. Health coaching not only embodies the residency redesign project goal of the P4 (Preparing the Personal Physician for Practice), but also fulfills requirements for the NCQA Standards for PCMH Recognition for which practices can be reimbursed for providing this teambased service. ${ }^{19}$ Programs in medium to large communities had greater exposure than densely or sparsely populated ones. One explanation may be that small practices are often in rural settings, and the likelihood of having PCMH certification increases with practice size. ${ }^{20}$ Finally, there was variation in the level of training of health coaches, reflecting the diversity of possible backgrounds. ${ }^{7}$

These results are important because they provide the only national assessment of training with health coaches in family medicine residencies. This wide adoption builds on a long tradition in family medicine education that values a multidisciplinary approach..$^{21,22}$ Furthermore, this study may be viewed as a proxy for resident exposure to new types of patient-centered practice workforce, and begs further investigation and work on increasing exposure, team training, and curricula focused on how best to work and train with new team members to improve patient outcomes.

Future work includes surveying the knowledge and attitudes of teambased care delivery and likelihood of using coaches after graduation. Studies that model the impact of health coach exposure on resident burnout, retention, and patient outcomes would inform future training models.

This study has several limitations including self-selection bias. Nonresponders may have lower or higher rates of health coach exposure and recall bias may skew results in favor of more exposure to health coaches. These results are only applicable to family medicine training programs. In summary, residents are widely exposed to health coaches, and those in level 3 NCQA PCMHs are most likely to be exposed. 
Table 1: Characteristics of Residency Programs Surveyed by CERA and Proportion With Resident Exposure to Health Coaches

\begin{tabular}{|c|c|c|}
\hline & $\begin{array}{l}\text { Distribution Within } \\
\text { Category (\%) }\end{array}$ & $\begin{array}{l}\% \text { of Programs Where Residents Had } \\
\text { Any Exposure to Health Coaches }\end{array}$ \\
\hline \multicolumn{3}{|l|}{ Type of Residency Program } \\
\hline University-based & 2.5 & 66.7 \\
\hline Community-based, university-affiliated & 16.9 & 56.1 \\
\hline Community-based, nonaffiliated & 64.5 & 70.5 \\
\hline Military & 11.2 & 55.6 \\
\hline Other & 5.0 & 75.0 \\
\hline \multicolumn{3}{|l|}{ Region of the Country } \\
\hline Puerto Rico & 0.8 & 100.0 \\
\hline New England & 5.3 & 76.9 \\
\hline Middle Atlantic & 12.3 & 60.0 \\
\hline South Atlantic & 13.1 & 75.0 \\
\hline East South Central & 3.3 & 62.5 \\
\hline East North Central & 16.8 & 63.4 \\
\hline West South Central & 10.2 & 56.0 \\
\hline West North Central & 11.1 & 70.4 \\
\hline Mountain & 8.2 & 65.0 \\
\hline Pacific & 18.9 & 67.4 \\
\hline \multicolumn{3}{|l|}{ Size of the Community** } \\
\hline Less than 30,000 & 7.0 & 58.8 \\
\hline 30,000 to 74,999 & 16.0 & 59.0 \\
\hline 75,000 to 149,000 & 17.3 & 78.6 \\
\hline 150,000 to 499,999 & 28.0 & 75.0 \\
\hline 500,000 to 1 million & 16.5 & 67.5 \\
\hline More than 1 million & 15.2 & 45.9 \\
\hline \multicolumn{3}{|c|}{$\%$ of Graduates From Non-US Medical Schools** } \\
\hline $0 \%$ to $24 \%$ & 57.0 & 69.6 \\
\hline $25 \%$ to $49 \%$ & 16.1 & 76.9 \\
\hline $50 \%$ to $74 \%$ & 13.6 & 51.5 \\
\hline $75 \%$ to $100 \%$ & 13.2 & 53.1 \\
\hline \multicolumn{3}{|l|}{ No. of Residents } \\
\hline Less than 19 & 33.3 & 63.0 \\
\hline 19 to 31 & 49.4 & 67.5 \\
\hline More than 31 & 17.3 & 69.0 \\
\hline
\end{tabular}

Chi-square test if amount of resident exposure varies across the group: $* * *=<.01, * *<.05, *<.1$.

$\mathrm{N}=240$ family medicine residency programs.

Data source: 2015 CERA survey. 
Table 2: PCMH Status of Family Medicine Residency Programs Surveyed by CERA

\begin{tabular}{|l|c|c|}
\hline \multicolumn{1}{|c|}{ PCMH Status } & Count & \% Where Residents Have Any Exposure as Part of Their Training \\
\hline Level 3 & 124 & $73.4^{* *}$ \\
\hline Level 2 & 23 & 52.2 \\
\hline Level 1 & 15 & 60.0 \\
\hline In the process of applying & 31 & 64.5 \\
\hline Not PCMH & 47 & $55.3^{*}$ \\
\hline
\end{tabular}

Chi-square test if the percentage for that category differs from all continuity sites: ${ }^{* *}=P<.05,{ }^{*}=P<.1$.

$\mathrm{N}=240$.

Data source: 2015 CERA survey.

Table 3: Health Coaches and Training Backgrounds

\begin{tabular}{|c|c|c|c|c|c|c|c|c|}
\hline & \multirow{2}{*}{$\begin{array}{l}\text { No. Using } \\
\text { Health } \\
\text { Coaches }\end{array}$} & \multicolumn{7}{|c|}{ \% Using Health Coaches With This Training Background } \\
\hline & & $\begin{array}{l}\text { Registered } \\
\text { Nurse }\end{array}$ & $\begin{array}{l}\text { Medical } \\
\text { Assistant }\end{array}$ & $\begin{array}{c}\text { Licensed } \\
\text { Practical } \\
\text { Nurse }\end{array}$ & Psychologist & $\begin{array}{l}\text { Social } \\
\text { Worker }\end{array}$ & $\begin{array}{l}\text { Trained } \\
\text { Health } \\
\text { Coach }\end{array}$ & $\begin{array}{c}\text { No } \\
\text { Specific }\end{array}$ \\
\hline $\begin{array}{l}\text { Used any health } \\
\text { coaches }\end{array}$ & 137 & $47.5 \%$ & $8.8 \%$ & $8.0 \%$ & $32.1 \%$ & $41.6 \%$ & $19.7 \%$ & $11.7 \%$ \\
\hline $\begin{array}{l}\text { Available to all } \\
\text { patients }\end{array}$ & 35 & $40.0 \%$ & $5.7 \%$ & $0 \% * * *$ & $40.0 \%$ & $45.7 \%$ & $14.3 \%$ & $8.3 \%$ \\
\hline $\begin{array}{l}\text { Specifically } \\
\text { chronic disease } \\
\text { management }\end{array}$ & 95 & $52.6 \% * *$ & $9.5 \%$ & $11.6 \% * *$ & $26.3 \% *$ & $37.9 \%$ & $24.2 \% * *$ & $12.6 \%$ \\
\hline $\begin{array}{l}\text { Specifically } \\
\text { obesity }\end{array}$ & 34 & $52.9 \%$ & $17.7 \% * *$ & $8.8 \%$ & $32.3 \%$ & $38.2 \%$ & $35.3 \% * * *$ & $8.8 \%$ \\
\hline $\begin{array}{l}\text { Specifically } \\
\text { mental health }\end{array}$ & 44 & $50.0 \%$ & $11.4 \%$ & $4.6 \%$ & $43.2 \% * *$ & $43.2 \%$ & $13.6 \%$ & $18.2 \% *$ \\
\hline $\begin{array}{l}\text { Specifically pain } \\
\text { management }\end{array}$ & 15 & $66.7 \% *$ & $26.7 \%$ **** & $6.7 \%$ & $66.7 \% * * *$ & $26.7 \%$ & $13.3 \%$ & $6.7 \%$ \\
\hline
\end{tabular}

Chi-square test: $* * *=P<.01, * *=P<.05, *=P<.1$.

Data source: 2015 CERA survey.

CORRESPONDING AUTHOR: Address correspondence to Dr Gastala, UI Health Mile Square Community Health Center, 1220 South Wood St, Chicago, IL 60608. 312-996-2000. reizinee@gmail.com.

\section{References}

1. Ward BW, Schiller JS, Goodman RA. Multiple chronic conditions among US adults: a 2012 update. Prev Chronic Dis. 2014;11:E62.

2. Østbye T, Yarnall KS, Krause KM, Pollak KI, Gradison M, Michener JL. Is there time for management of patients with chronic diseases in primary care? Ann Fam Med. 2005;3(3):209214.

3. Haynes RB, McDonald HP, Garg AX. Helping patients follow prescribed treatment: clinical applications. JAMA. 2002;288(22):2880-2883.

4. Yarnall KSH, Pollak KI, Østbye T, Krause KM, Michener JL. Primary care: is there enough time for prevention? Am J Public Health. 2003;93(4):635-641.
5. Willard-Grace R, Chen EH, Hessler D, et al. Health coaching by medical assistants to improve control of diabetes, hypertension, and hyperlipidemia in low-income patients: a randomized controlled trial. Ann Fam Med. 2015;13(2):130-138

6. Kivelä K, Elo S, Kyngäs H, Kääriäinen M. The effects of health coaching on adult patients with chronic diseases: a systematic review. Patient Educ Couns. 2014;97(2):147-157.

7. Ghorob A. Health coaching: teaching patient how to fish. Fam Pract Manag. 2013;20(3):4042.

8. Jonk Y, Lawson K, O'Connor H, et al. How effective is health coaching in reducing health services expenditures? Med Care. 2015;53(2):133-140.

9. Chen EH, Thom DH, Hessler DM, et al. Using the Teamlet Model to improve chronic care in an academic primary care practice. J Gen Intern Med. 2010;25(S4)(suppl 4):S610-S614.
10. Bartels SJ, Pratt SI, Aschbrenner KA, et al. Pragmatic replication trial of health promotion coaching for obesity in serious mental illness and maintenance of outcomes. Am J Psychiatry. 2015;172(4):344-352

11. Daumit GL, Dickerson FB, Wang NY, et al. A behavioral weight-loss intervention in persons with serious mental illness. N Engl J Med. 2013;368(17):1594-1602.

12. Green CA, Yarborough BJ, Leo MC, et al. The STRIDE weight loss and lifestyle intervention for individuals taking antipsychotic medications: a randomized trial. Am J Psychiatry. 2015;172(1):71-81.

13. Vale MJ, Jelinek MV, Best JD, et al; COACH Study Group. Coaching patients On Achieving Cardiovascular Health (COACH): a multicenter randomized trial in patients with coronary heart disease. Arch Intern Med. 2003;163(22):2775-2783. 
14. Damschroder LJ, Lutes LD, Kirsh S, et al. Small-changes obesity treatment among veterans: 12-month outcomes. Am J Prev Med. 2014;47(5):541-553.

15. Thom DH, Hessler D, Willard-Grace R, et al. Health coaching by medical assistants improves patients' chronic care experience. Am J Manag Care. 2015;21(10):685-691.

16. Bodenheimer T, Laing BY. The teamlet model of primary care. Ann Fam Med. 2007;5(5):457461.

17. Mainous AG III, Seehusen D, Shokar N. CAFM Educational Research Alliance (CERA) 2011 Residency Director survey: background, methods, and respondent characteristics. Fam Med. 2012;44(10):691-693.
18. National Committee for Quality Assurance. NCQA Patient-Centered Medical Home (PCMH) Recognition. http://ncqa.org/Programs/ Recognition/Practices/PatientCenteredMedicalHomePCMH.aspx. Accessed April 23, 2017.

19. PCMH Standards and Guidelines. http:// www.acofp.org/acofpimis/Acofporg/Apps/2014 PCMH_Finals/Tools/2_PCMH_Recognition_2014_Standards_and_Guidelines.pdf. Accessed April 23, 2017.

20. Liaw WR, Jetty A, Petterson SM, Peterson LE, Bazemore AW. Solo and small practices: a vital, diverse part of primary care. Ann Fam Med. 2016;14(1):8-15.
21. Accreditation Council for Graducate Medcial Education. ACGME Program Requirements for Graduate Medical Education in Family Medicine. https://www.acgme.org/Portals/0/PFAssets/ProgramRequirements/120 family medicine_2016.pdf. Accessed April 23, 2017.

22. Axelson A, Xenakis S, Thompson K, et al. Integrating behavioral medicine into primary care GME: a necessary paradigm for 21st century ambulatory practice. Health Affairs Blog. http://healthaffairs.org/blog/2015/04/24/ integrating-behavioral-medicine-into-primarycare-gme-a-necessary-paradigm-for-21st-century-ambulatory-practice/. Posted April 24, 2015. Accessed April 23, 2017 